\section{ESPACIOS Y PRÁCTICAS DE LA MILITANCIA CATÓLICA EN BAHÍA BLANCA (ARGENTINA) A FINES DE LOS '60 Y PRINCIPIOS DE LOS ' 701}

\author{
SPACES AND PRACTICES OF CATHOLIC MILITANCY IN BAHÍA BLANCA \\ (ARGENTINA) IN THE LATE '60s AND EARLY '70s²
}

\section{Virginia Lorena Dominella ${ }^{3}$}

ARGENTINA

Palabras clave: juventud católica, militancia, Bahía Blanca

Keywords: catholic youth, militancy, Bahía Blanca

\section{Resumen}

Este artículo se propone reconstruir y analizar las prácticas y espacios de encuentro, acción y construcción social y política de un grupo de jóvenes pertenecientes a la Juventud Universitaria Católica (JUC) en Bahía Blanca (Argentina), entre los últimos años de la década de 1960 y la primera mitad de la década de 1970. A partir de dicho análisis, se intenta identificar las marcas locales de aquella experiencia, así como las particularidades de la militancia católica en el marco del movimiento de activación juvenil bahiense en aquellos años. Para ello, se utiliza una metodología de carácter cualitativo.

\footnotetext{
Abstract

This paper aims at reconstructing and analyzing the practices and meeting and action spaces, social and political construction of a group of young people from the Catholic University Youth (JUC) in Bahia Blanca (Argentina), during the last years of the 1960s and the first half of the 1970s. Based on this analysis, it is attempted to identify the local marks left by that experience as well as the characteristics of the militant Catholic movement within the framework of the bay juvenile activation movement in those years. A qualitative methodology is used to reach the objective.
}

Páginas 29-44
1 Este artículo forma parte de la investigación desarrollada en el marco de la tesis de grado recientemente defendida, titulada "El fermento en la masa. La Juventud Universitaria Católica en Bahía Blanca, entre la efervescencia política y la oleada represiva de la Triple A (19681975)". Una primera versión del presente trabajo fue discutida en la mesa "Juventud y participación política en Argentina y en América Latina. Formas de compromiso político, militancia y movilización social de los jóvenes entre la década del ` 60 y la actualidad" de las XII Jornadas Interescuelas y/o Departamentos de Historia, San Carlos de Bariloche, Argentina, 28 - 31 de octubre de 2009.

2 Traducción de Blanca Stella Giraldo. Revisión Centro de Traducción del Instituto de Idiomas UAM.

3 Profesora y Licenciada en Historia por la Universidad Nacional del Sur, Bahía Blanca, Argentina. Becaria del Consejo Nacional de Investigaciones Científicas y Técnicas (CONICET).E-mail: v_dominella@yahoo.com.ar.

Fecha recibido: 14-05-10

Fecha aprobado: 15-07-10

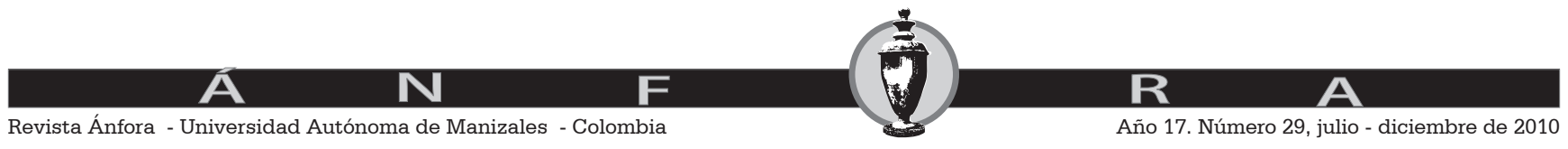




\section{Introducción}

El objetivo de este trabajo es reconstruir y analizar la militancia de un grupo de jóvenes pertenecientes a la Juventud Universitaria Católica (JUC) en Bahía Blanca, desde fines de los '60 hasta la desestructuración de esa militancia, en un contexto atravesado por la violencia política ejercida por la Triple A4, primero, y la última dictadura militar (1976-1983), después, intentando mostrar las marcas de lo local en dicho recorrido histórico. La investigación se centra en las prácticas y en los espacios de encuentro, acción y construcción política de estos jóvenes.

Esta militancia cristiana tuvo lugar en un contexto histórico marcado por diversos procesos. Por un lado, desde la década del '60 la sociedad argentina, como gran parte del mundo occidental, asistía a una revolución cultural que involucró a las actividades artísticas e intelectuales, y a todo un modo de vida, costumbres y comportamiento. Como parte del mismo proceso, al cuestionamiento de la tradicional superioridad del hombre sobre la mujer se sumó el de la superioridad de los adultos sobre los jóvenes. La juventud, sujeto de esta revolución, se convirtió en un grupo social independiente, lo que implicó la resignificación del ser joven: ya no era una etapa de transición entre la niñez y la adultez sino el momento culminante del desarrollo humano (Burkart, 2007: 5-6).

La irrupción, hacia fines de los '60, de una cultura juvenil en la Argentina asumió un tono general crítico frente al orden social y político, que se expandió en esos años, apoyado en tradiciones diversas e incluso contradictorias que, sin embargo, lograron articularse en el imaginario juvenil, sosteniendo prácticas y actitudes (Cattaruzza, 1997: 109). A partir de la crítica al "sistema" muchos jóvenes asumieron una actitud militante, buscando inscribirse en alguna tradición y recuperar líneas de reflexión que venían sacudiendo a la izquierda. Otros jóvenes no se incorporaron a agrupaciones políticas pero, a partir de un conjunto heterogéneo de autores, textos y referencias ocasionales, contribuyeron a alentar una actitud contestataria que aunque imprecisa, e incluso débil, operaba efectivamente en la conciencia de aquellos jóvenes (Cattaruzza, 1997: 106).

Por otro lado, en esos años tenía lugar un proceso de renovación de la Iglesia católica a partir de los papados de Juan XXIII y Pablo VI, el Concilio Vaticano II (1962-1965), la II Conferencia General del Episcopado LatinoAméricano en Medellín (1968) y la II Asamblea Extraordinaria del Episcopado Argentino en San Miguel (1969). Dicha renovación se dio en diversos ejes: una apertura al mundo, una atención preferencial a los pobres ${ }^{5}$ y un espíritu más horizontal y participativo, en el cual la corresponsabilidad de todos los sectores de la Iglesia en la tarea evangelizadora se hacía una exigencia de los tiempos. Los tres ejes remitían al compromiso histórico por la liberación nacional y social que se perfilaba como ideal para grandes sectores de la juventud argentina (Politi, 1992: 121).

En Medellín, la Iglesia reconocía el papel decisivo de la juventud en el proceso de transformación del continente y su rol irremplazable en la misión profética de
4 La Alianza Anticomunista Argentina era un grupo armado y protegido por el gobierno de Isabel Perón (1974-1976) para liquidar a la izquierda dentro y fuera del peronismo (De Riz, 1987). El peronismo es un amplio y heterogéneo movimiento político surgido en 1945 en la Argentina. Su líder, Juan Domingo Perón, fue presidente de la nación en dos mandatos consecutivos entre 1946 y 1955, año en que fue derrocado por un golpe de estado. Su gobierno, de carácter populista, se caracterizó por la inclusión de los sectores populares en el plano social, político y simbólico. Luego de un largo exilio de 18 años, volvió al país y al poder - gobiernos de Héctor Cámpora (mayo-julio de 1973) y de J. D. Perón (octubre de 1973junio de 1974) - en un contexto marcado por profundos conflictos sociales y políticos, así como por enfrentamientos cada vez más violentos entre las distintas fracciones del movimiento peronista. Después de su muerte, en julio del ' 74 , su mujer, la vicepresidenta Isabel Perón, lo sucedió en el gobierno, consolidando el avance de la derecha peronista y del terror paraestatal.

5 La expresión "opción preferencial por los pobres" fue consagrada años después, en la Conferencia de Obipos LatinoAméricanos de Puebla (1979).

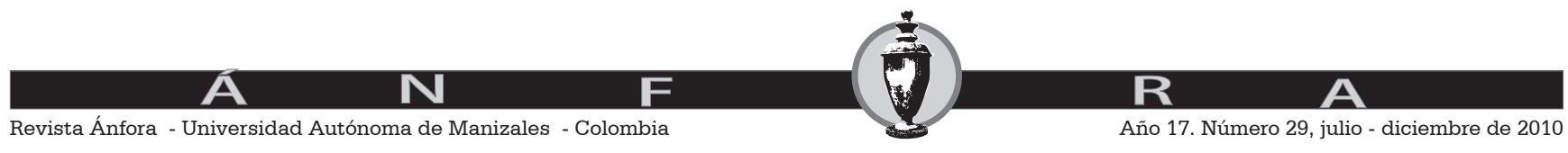


la Iglesia, en tanto constituía no sólo el grupo más numeroso de la sociedad latinoAméricana, sino fundamentalmente, un nuevo cuerpo social, portador de sus propias ideas, valores y dinamismo interno, que buscaba participar activamente, asumiendo nuevas responsabilidades y funciones, dentro de la comunidad latinoAméricana. Se destacaba que "la juventud, particularmente sensible a los problemas sociales, reclama cambios profundos y rápidos que garanticen una sociedad más justa" (Segunda Conferencia General del Episcopado LatinoAméricano, 1969: 74). En este marco, la Iglesia debía dar respuesta a los reclamos pastorales de los jóvenes, reconocer la autonomía propia de los seglares a los movimientos católicos de juventud y estimular su acción en la transformación de las personas y las estructuras.

Al mismo tiempo, los obispos reunidos en Medellín destacaban el papel de los laicos ante la compleja realidad latinoAméricana y reconocían que lo típicamente laical estaba constituido, en efecto, por el compromiso en el mundo, que debía estar marcado por un signo de liberación, humanización y desarrollo. En la opción de su compromiso temporal el laico gozaba de autonomía y responsabilidad propias, como lo reconocían las encíclicas Gaudium et Spes y Populorum Progressio (Segunda Conferencia General del Episcopado LatinoAméricano, 1969: 126). La Iglesia debía promover con especial énfasis y urgencia la creación y el apoyo de movimientos laicos en los ambientes donde se elaboraba y decidía en gran parte el proceso de liberación y humanización de la sociedad.

En síntesis, los jóvenes se convirtieron en un nuevo sujeto social que ocupó el centro de la escena en el campo cultural y político, se constituyeron en el sujeto que encarnaba la expectativa y la esperanza revolucionaria, y dentro de la Iglesia, adquirían protagonismo y autonomía en tanto jóvenes y laicos que estaban llamados a desempeñar un rol fundamental en el camino de liberación. Estos procesos nos permiten comprender el escenario en el que se desarrolló la militancia de los jóvenes jucistas bahienses, entre fines de la década del ' 60 y principios de la década siguiente, que constituye el objeto del presente trabajo.

\section{La JUC en Bahía Blanca}

El sujeto de esta historia es un grupo de cristianos pertenecientes mayoritariamente a la Juventud Universitaria Católica ${ }^{6}$, una de las ramas especializadas de la Acción Católica. La JUC fue, precisamente, una de las organizaciones que protagonizó la renovación post-conciliar pero, en realidad, distaba de ser nueva; por el contrario, se enraizaba en la dinámica del desarrollo del movimiento católico en las décadas anteriores. La disposición en ramas estaba vinculada a la idea de ámbitos de acción pastoral cruzada con una base territorial: los mundos del trabajo (Juventud Obrera Católica-JOC), de la cultura y de la educación (Juventud de Estudiantes Católicos-JEC y Juventud Universitaria Católica-JUC) y el agrario (Movimiento Rural de Jóvenes de Acción Católica-MIJARC) (Mallimaci, Cucchetti y Donatello, 2006: 15).

La JUC nucleaba a muchos jóvenes en distintas ciudades de la Argentina,
6 El trabajo se realiza sobre la base de la confrontación de distintos tipos de fuentes: documentos del archivo de la Dirección de Inteligencia de la Policía de la Provincia de Buenos Aires (DIPBA) a disposición de la Comisión Provincial por la Memoria, artículos de diarios y revistas locales, y fuentes orales. En este último caso, la muestra está conformada por los testimonios de diez hombres y mujeres que integraron la JUC en Bahía Blanca, entre fines de los ' 60 y 1975, con diversas trayectorias en cuanto al origen familiar (en términos de tradiciones políticas y religiosas), el período de participación en la JUC, los tipos y los espacios de militancia, las opciones ideológicopolíticas, los caminos recorridos a partir del comienzo de la violencia política y la vinculación actual con el mundo católico. También se incluyen los testimonios de Norma y Mónica, que no integraban la JUC. Norma era en aquella época una joven religiosa, referente y compañera de militancia en Villa Nocito de muchos de estos jóvenes. Mónica era integrante de la JEC. Ambas forman parte del grupo actual de amigos, integrado mayormente por ex jucistas, que reconoce su origen en las ideas y la militancia compartida.

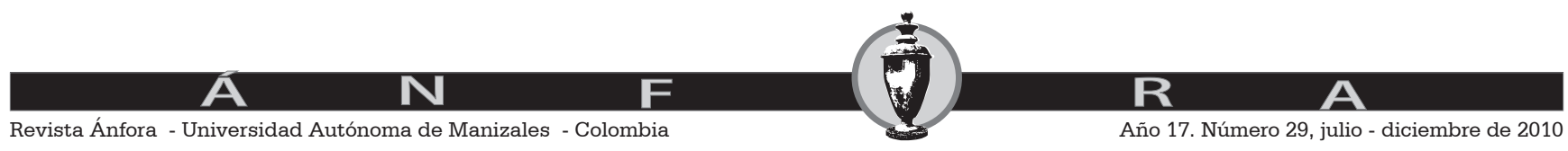


como Buenos Aires, Tucumán, Córdoba o Bahía Blanca, y adoptó distintos nombres en América Latina. Estos grupos pertenecían al Movimiento Internacional de Estudiantes Católicos-Juventud Estudiantil Católica Internacional, que era la convergencia de dos movimientos especializados internacionales que trabajaban con estudiantes (MIEC y JECI) que, a diferencia de lo que sucedía en el resto de los continentes en los que se mantenían separados, en América Latina se unificaron. Existían instancias de articulación, coordinación y comunicación de los grupos de jóvenes católicos en distintos niveles: el Secretariado Nacional, que iba rotando de una provincia a otra; el Secretariado LatinoAméricano, que en ese momento funcionaba en Lima (Perú) y el Secretariado Mundial de la JECI con sede en París (Francia).

La JUC estaba formada por grupos de revisión de vida que se reunían semanalmente, en casas particulares y en compañía de un sacerdote asesor, para reflexionar sobre la realidad a la luz del Evangelio mediante la metodología del Ver, Juzgar y Actuar, también utilizada por la JEC y la JOC. En palabras de una integrante de la JEC bahiense:

“¿Qué está pasando? Está pasando esto. ¿Qué dice el mensaje cristiano respecto de esta realidad? Dice tal cosa. ¿Y por lo tanto qué tengo que hacer? Ver, Juzgar y Actuar, esa era la pedagogía con lo cual siempre terminabas en el Actuar [...] ¿Qué hacemos nosotros?...¿qué hacemos nosotros en la escuela?, ¿qué hacemos nosotros en el barrio?, ¿qué hacemos en la universidad?" ".

Se trataba de una reflexión transformadora, es decir, de revisar en conjunto las propias prácticas religiosas, sociales, políticas vinculadas al intento de transformación social, juzgar su pertinencia desde el Evangelio y darles profundidad. Se buscaba que la fe interpelara personalmente y en forma cotidiana, pero no de modo individual sino con otros.

La revisión de vida tenía implicancias significativas. Por un lado, "ya no parte de dogmas y verdades para ser llevadas a la acción sino que a partir de la realidad, buscan cómo llevar adelante su apostolado" (Mallimaci, 1992: 342). Esto significa que la doctrina católica es releída a partir de la militancia en un contexto particular y que la prioridad reside en el análisis de las problemáticas específicas del medio de acción por los militantes, antes que en las directivas de la institución ${ }^{8}$. Se trata, en definitiva, de un modo radicalmente distinto de vivencia de la fe y de relación con el Dios en el que se cree. Esta reflexión "de abajo para arriba", que tiene como punto de partida la vida y no el Evangelio, supone un encuentro con Dios en una realidad históricamente situada, con lo cual "no hay posibilidad de evasión".
7 Entrevista a Mónica, 30/07/08. Los nombres de los entrevistados fueron cambiados, con excepción de las figuras públicas, cuya identificación resulta inevitable.

8 Esta pedagogía, sumada a la pertenencia de la JUC al MIECJECI, permitirían explicar en parte el tipo de relación particular que mantuvo la JUC con la jerarquía eclesiástica, que la diferencia de la Acción Católica tradicional. Mientras ésta era una suerte de brazo largo del episcopado, los testimonios coinciden en señalar que la JUC y el obispo tenían un vínculo como mínimo distante, sin demasiado contacto. Por el contrario, los jóvenes católicos mantuvieron una actitud crítica frente a la jerarquía.

9 Entrevista a José Zamorano, 19/09/09. El Padre Zamorano fue asesor de la JUC en Bahía Blanca entre 1967 y 1975.

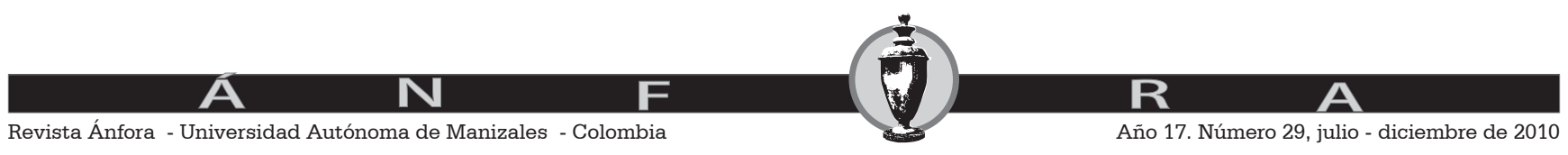


Por otro lado, supone una concepción integral de la vivencia de la fe que no se limita a la esfera de las creencias sino que expande su influencia a toda la vida del militante, que debe ser guiada por los principios religiosos (Giménez Béliveau, 2005: 221). Este catolicismo vivido "integralmente" debía penetrar en cada uno de los "ambientes" donde los militantes desarrollaban su compromiso. En este sentido, la concepción que guiaba su acción era la del "fermento en la masa", que implicaba la inserción en la realidad con un estilo propio, esto es, animados por la fe y compartiendo una intensa vida comunitaria, pero sin segregarse de los demás hombres.

En las reuniones, el asesor era el adulto que acompañaba la revisión de vida y concretamente, el intento de descubrir en la realidad que se analizaba los "brotes de la presencia de Dios en la historia" y "tratar de vincular [la] con la Palabra [de Dios]"10. Y, dada su preparación teórica como clérigo, podía aportar elementos de la teología a la formación de los jóvenes. Sin embargo, la influencia del Padre Zamorano fue más profunda dada su cercanía, su acompañamiento personal de los jóvenes y su postura pastoral clara en la línea de renovación de la Iglesia

El sacerdote asesor era quien además celebraba las misas de los sábados en La Pequeña Obra ${ }^{11}$. Estas celebraciones eran momentos de encuentro de todos los jóvenes de los distintos grupos de la JUC y se caracterizaban porque la homilía ${ }^{12}$ tenía una parte compartida y estaba fuertemente vinculada con cuestiones de la realidad. Además, en el verano compartían campamentos donde se preparaban temas de formación y reflexión, y se constituían en momentos importantes de socialización para los jóvenes.

Durante la primera mitad de la década del '70, la JUC bahiense -que llegó a reunir alrededor de 40 personas- era un grupo consolidado, lo que se veía reflejado en la participación de muchos de sus miembros en los equipos nacional, latinoAméricano e internacional del movimiento y en el acompañamiento dado a grupos similares en formación en otros lugares del país. No obstante, para dimensionar y valorar la experiencia bahiense y su protagonismo dentro del movimiento, es necesario ubicarlo en su contexto. La JUC que comenzó a constituirse en 1967 con el acompañamiento de los sacerdotes José Zamorano y Emilio Flores continuaba o recreaba, con nuevos integrantes, nuevos asesores y en otro contexto, una experiencia de JUC bahiense que había sido fuerte pero se encontraba desarticulada, a raíz del éxodo de militantes católicos que se incorporaban a agrupaciones de izquierda y del abandono del ministerio sacerdotal por parte del asesor. Otro tanto ocurría, simultáneamente y por motivos semejantes, con diversos grupos de JUC afianzados en otras ciudades del país.

La experiencia bahiense participaba de un proceso de renovación que atravesaba la JUC en todo al país, al calor del aggiornamiento eclesial, caracterizado por el afianzamiento de la corriente teológico-social de la encarnación y el compromiso, la radicalización política de ciertos militantes, la reflexión alrededor de las nuevas formas de compromiso y la revisión de vida (Habegger, 1970). Como consecuencia de ello, los jucistas bahienses compartían una
10 Entrevista a José Zamorano, 19/09/09.

11 Era un centro pastoral donde también funcionaban grupos Scouts y Guías de los que muchos jóvenes de la JUC y de la JEC eran dirigentes.

12 La homilía es el momento de la misa donde se reflexiona sobre las lecturas del Antiguo y del Nuevo Testamento que corresponden a cada día. Generalmente la realiza el sacerdote.

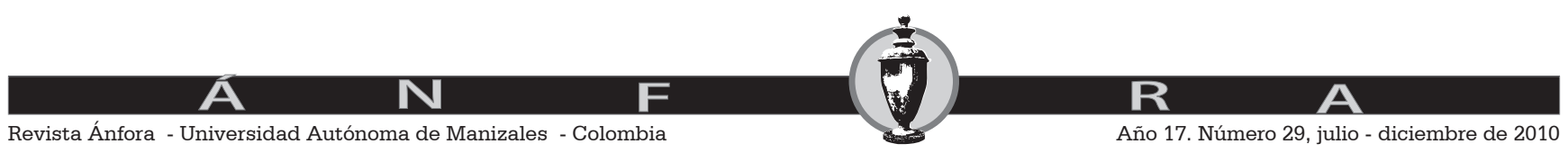


visión encarnada de la fe que implicaba el cuestionamiento a las estructuras económico-sociales injustas generadoras de opresión, y la necesidad de "actuar", es decir, de asumir un compromiso concreto orientado a la liberación, a la transformación social, política y económica, a la construcción del Reino de Dios en la tierra, de una sociedad más justa, sin exclusiones, sin explotación.

Estas posturas llevaron a la JUC a emprender una serie de iniciativas y actividades que tenían que ver, básicamente, con denunciar o expresar públicamente sus críticas contra acciones de la jerarquía eclesiástica, del gobierno militar, de La Nueva Provincia ${ }^{13}$ y de las fuerzas de seguridad, por medio de volantes o comunicados.

Sin embargo, más allá de estas acciones conjuntas, los militantes católicos no tenían un apostolado común como JUC. El grupo cristiano no era un espacio de acción sino de reflexión, aunque interpelaba a sus miembros a asumir un compromiso. Sólo así cobraba sentido la revisión de las propias prácticas en sus comunidades. El "actuar" tenía que ver con transformar la realidad desde el propio lugar. De modo que el compromiso tomaba distintas formas y estaba estrechamente unido con el ambiente donde cada uno se desenvolvía: el trabajo, el barrio periférico, la universidad, etc. Por ello, podemos reconocer diferentes perfiles y espacios de militancia: estudiantil (la universidad), barrial, sindical, eclesial (como dirigentes Scouts o Guías), social, política, político-militar ${ }^{14}$.

\section{La militancia en la universidad}

Un espacio central de la militancia de los integrantes de la JUC fue la Universidad Nacional del Sur (UNS). En esos años, la Universidad se constituyó en "caja de resonancia de nuevas formas de compromiso de los cristianos, condicionados por su extracción social y el medio en que actúan y dinamizados por la corriente posconciliar" (Habegger, 1970: 141). Hacia mediados de los ' 60 , en el clima de politización y radicalización de la JUC en centros urbanos como Buenos Aires, Tucumán y Bahía Blanca, se había iniciado el diálogo católico-marxista, el ingreso de muchos jucistas en organizaciones de izquierda y se había levantado la consigna de trabajar con los no creyentes. Se planteaba que el militante cristiano no podía comprometerse sin asumir personalmente una visión ideológica, un compromiso a nivel personal (Habegger, 1970).

En la UNS confluían agrupaciones que actuaban como frentes estudiantiles partidarios y eran la expresión del proceso de cambio, movilización y politización del movimiento estudiantil que tenía lugar en aquellos años. En general, estas agrupaciones compartían un posicionamiento antidictatorial ${ }^{15}$ y un discurso revolucionario/combativo: los Grupos Socialistas -que seguían la línea del Partido Revolucionario de los Trabajadores-Ejército Revolucionario del Pueblo (PRT-ERP) ${ }^{16}$-, el Frente de Acción Estudiantil (FAE) -ligado a los
13 Diario bahiense fundado en 1898 por Enrique Julio y dirigido, desde 1956, por Diana Julio de Massot, nieta del fundador. La empresa periodística fue ampliada con la adquisición en 1958 de una radio -LU2 Radio Bahía Blanca- y en 1965 de un canal de televisión -LU80 Canal 9 Telenueva-, convirtiéndose de esa manera en la voz periodística hegemónica en la ciudad. Durante esos años, el diario mantuvo un discurso antiperonista y pro-militar. Las mismas fuerzas de seguridad reconocerían en 1976 la importancia fundamental del matutino en tanto único medio real de difusión y acérrimo enemigo del marxismo, del "tercermundismo" - o de la Iglesia post-conciliar - y del peronismo (Zapata, 2008).

14 No pretendo agotar en este trabajo la reconstrucción de la totalidad de espacios de acción en el que se involucraron los militantes de la JUC bahiense. Sólo me centraré en dos, Villa Nocito y la UNS, por razones de espacio, porque fueron en efecto dos ámbitos de militancia clave para este grupo, porque allí confluyeron prácticas distintas (sociales, políticas, eclesiales) y porque a ellos se refirieron la gran mayoría de los testimonios y de la información que he podido recabar hasta aquí.

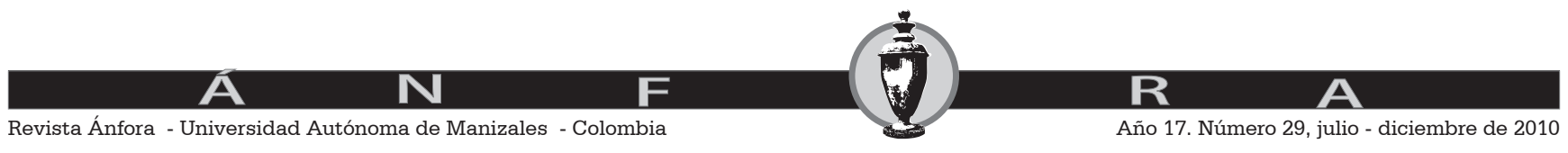


sectores más combativos de la clase obrera nucleados en torno a la CGT de los Argentinos ${ }^{17}$-, la Tendencia Estudiantil Socialista Revolucionaria (TERS) -que continuaba el programa y posicionamiento trotskista del partido Política Obrera-, el Frente Estudiantil Nacional (FEN) -que militaba en el peronismo revolucionario ${ }^{18}$-, la Agrupación Universitaria de Acción Liberadora (AUDAL) -adherida al Frente de Agrupaciones Universitarias de Izquierda (FAUDI) y vinculada al Partido Comunista Revolucionario ${ }^{19}$ - y la Agrupación Estudiantil Reformista (AER) -que formaba parte del Movimiento de Acción Reformista (MOR) y estaba vinculada al Partido Comunista Argentino ${ }^{20}$.

Para muchos cristianos, la opción por la militancia universitaria se hallaba justificada por la idea de que cada cual debía comprometerse en su lugar de trabajo, en su medio, idea compartida en los grupos cristianos, y discutida en la universidad. Los jucistas bahienses militaron en diversas agrupaciones universitarias. AUDAL tuvo un fuerte componente de militantes católicos que participaron en su formación y dejaron su impronta en sus principios. Según Juan Carlos, militante jucista integrante de AUDAL, éstos estaban "sacados de Medellín"21. Juan Carlos recordaba que en los primeros años de la década del '70, buena parte de los jóvenes de la JUC participaban en los Grupos Socialistas y en la TERS. En muchos casos, desde fines de los ' 60 hasta el advenimiento de la oleada represiva de la Triple A, los mismos jóvenes militaron en diferentes agrupaciones: en el PRT antes o después del V Congreso ${ }^{22}$, en AUDAL y hacia 1973 se incorporaron a la Juventud Universitaria Peronista. Otros desarrollaron su actividad política en AUDAL pero se alejaron durante un tiempo de esta agrupación para formar la Tendencia Antiimperialista Revolucionaria (TAR) -integrada en parte por militantes próximos al PRT-ERP-y retornaron más tarde a la primera. Hubo también quienes comenzaron militando en Nueva Línea de Acción -que los Servicios de Inteligencia tomaban como sinónimo de los Grupos Socialistas- y luego dejaron la militancia en la Universidad y pasó a trabajar en la Juventud Trabajadora Peronista, la línea sindical del peronismo revolucionario. Por último, parte de este grupo de militantes católicos pasaron por el Peronismo de Base ${ }^{23}$ durante el '71-72, antes de que un grupo confluyera en la Juventud Peronista.

Pero más allá de las trayectorias individuales cambiantes, en un proceso que Juan Carlos define como de "encanto y desencanto", esta diversidad muestra que en la JUC convivían -aunque con tensiones- militantes de agrupaciones que seguían distintas líneas políticas: del PRT-ERP, del PCR, del peronismo revolucionario.

En 1973, con la caída del gobierno militar y la vuelta del peronismo al poder, el espacio universitario bahiense comenzó un proceso que Patricia Orbe caracteriza como "revolución peronista". El ministro de educación Jorge Taiana designó como interventor al abogado Víctor Benamo, cercano a la Juventud Peronista. Con él se abría una etapa de gran protagonismo del peronismo revolucionario en la UNS y de reformas administrativas y curriculares que apuntaban a hacer posible la participación de la Universidad en la construcción del socialismo nacional (Orbe, 2007).
15 La dictadura a la que se oponían era la autodenominada Revolución Argentina que, instaurada con el golpe militar de junio de 1966, se extendió hasta 1973 bajo las presidencias de facto de Juan Carlos Onganía, Roberto Levingston y Alejandro Lanusse.

16 El PRT fue fundado en 1965 luego de la unión de dos organizaciones: Palabra Obrera -de tendencia trotskista, nacida en las urbes industriales- y el Frente Revolucionario IndoAméricano y Popular -nacionalista y antiimperialista, abocado a las problemáticas de los trabajadores del norte argentino. En el V Congreso partidario, celebrado en 1970 , un sector del PRT conocido como PRT El Combatiente fundó el ERP (Giménez, 2008).

17 Nacida en 1968 y liderada por Raimundo Ongaro, expresó una ruptura en la columna vertebral de la burocracia sindical peronista. Insinuaba un nuevo tipo de sindicalismo empeñado en un pacto ideológico pluralista, antiimperialista, propenso a una reconstrucción "desde las bases" y promotor de iniciativas de amplia coordinación de luchas sociales y políticas (Bozza, 2002: 148).

18 Dentro del amplio espectro político del peronismo, el peronismo revolucionario o la izquierda peronista incluía a la Juventud Peronista (JP) y sus aliados: la Juventud Trabajadora Peronista (JTP), la Juventud Universitaria Peronista (JUP), la Unión de Estudiantes Secundarios (UES), el Peronismo de Base (PB), los sindicatos rebeldes de la provincia de Córdoba y organizaciones armadas como los Montoneros, las Fuerzas Armadas Revolucionarias (FAR) y las Fuerzas Armadas Peronistas (FAP) (De Riz, 1987).

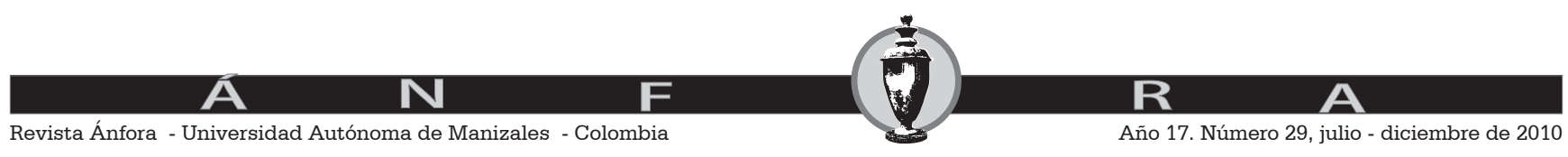


En este nuevo marco, la mayoría de los jucistas bahienses que militaban políticamente pasaron a enrolarse en agrupaciones que conformaban la Tendencia Revolucionaria del Peronismo, dentro y fuera de la universidad: JUP, JP territorial, JTP. Entre ellos encontramos jóvenes que no habían tenido militancia política previa y otros que habían militado en agrupaciones universitarias ligadas al PRT o al PCR y que ahora (re)descubrían el peronismo en un contexto que mostraba a quienes querían estar con el pueblo que éste era peronista y que los procesos revolucionarios partían de las peculiaridades de cada pueblo y de su historia. Si "ir al pueblo" y "estar con los pobres" significaba en Chile encontrarse con el socialismo y el comunismo, en Argentina se trataba de relacionarse con el movimiento peronista (Mallimaci, Cucchetti y Donatello, 2006: 15).

Al mismo tiempo, hubo militantes de las agrupaciones universitarias marxistas que pasaron por la JUC que siempre se mantuvieron al margen del peronismo y que, incluso, profundizaron su militancia en otros espacios, como el PRT-ERP.

Este escenario heterogéneo desde el punto de vista de las trayectorias político-ideológicas asumidas por los jóvenes católicos, complejiza la mirada respecto de la relación entre catolicismo renovador y peronismo revolucionario, que fuera objeto de reflexión por parte de diferentes protagonistas de la época y de análisis por varios cientistas sociales ${ }^{24}$. Las trayectorias personales atravesadas por el "encanto y desencanto" con distintas agrupaciones políticas y la existencia de militantes bahienses de origen cristiano comprometidos con la transformación social desde agrupaciones vinculadas al marxismo, como el PCR o el PRT-ERP, enriquece el panorama. No deja de ser interesante esta reflexión a pesar de que, por un lado, la adscripción a la línea de la JP-Montoneros ${ }^{25}$ haya sido, de hecho, el posicionamiento político mayoritario y que se haya manifestado de modo cada vez más excluyente entre los miembros de la JUC bahiense; y, por el otro, que las otras trayectorias políticas hayan coincidido con el tiempo con una mayor desvinculación de los ámbitos eclesiales.

Estrechamente vinculado a la actividad política universitaria, el Pensionado Católico se constituyó en un espacio significativo de la militancia bahiense. No debe perderse de vista que durante el período dictatorial de 1966-1973, la militancia universitaria, reprimida y excluida de los canales de participación democrática, se había visto obligada a explotar otros ámbitos de sociabilidad, donde aprendió a articular estructuras políticas más horizontales y abiertas (Orbe, 2007). En este sentido, había ciertos lugares que funcionaban como espacios de encuentro y discusión política.

Según los relatos de los militantes católicos que vivieron en el Pensionado de Zapiola 428, éste había sido iniciativa de la JUC de la generación anterior a la de fines de los '60-principios de los ' 70 y fue comprado gracias al dinero aportado por la organización católica Adveniat. Según otras versiones, la adquisición se logró mediante las cuotas de los pensionistas. La residencia estudiantil católica fue puesta a nombre del arzobispado de Bahía Blanca, pero administrada de manera autónoma por los jóvenes jucistas, acompaña-
19 Surgió a principios de 1968 a partir de un grupo de ex militantes del Partido Comunista argentino que denunciaron que el "revisionismo" del partido había traicionado la política revolucionaria marxista-leninista. Simpatizaban con el maoísmo y estaban a favor de una estrategia insurreccionalista (Orbe, 2007).

$20 \mathrm{El}$ movimiento estudiantil responde. (1971, abril). Revista Graphos, Bahía Blanca, año II, no 5 .

21 Entrevista a Juan Carlos, 29/07/08.

22 El PRT en Bahía Blanca tuvo dos etapas: una de formación, entre 1965 y 1969; y otra, a partir de 1970, año del V Congreso y de la constitución del ERP, con el surgimiento del PRT-ERP en la ciudad, de la mano de un nuevo programa, nuevos militantes y nuevas prácticas (Giménez, 2008).

23 Organización política creada en 1968, orientada el trabajo de masas, que aglutinó a militantes obreros combativos, sindicatos y comisiones de base en importantes fábricas y centros urbanos del país (Bozza, 2002).

24 Entre los que podemos mencionar: Concatti, R. (1972). Nuestra opción por el peronismo. Mendoza, Argentina: Sacerdotes para el Tercer Mundo. Mugica, C. (1973). Peronismo y Cristianismo. Buenos Aires, Argentina: Editorial Merlín. Lanusse, L. (2005). Montoneros. El mito de los doce fundadores. Buenos Aires, Argentina: Vergara.

25 Montoneros era una organización político-militar de identidad peronista que se dio a conocer públicamente en mayo de 1970 con el secuestro y asesinato del ex presidente de facto, Teniente General Pedro Eugenio Aramburu. Su objetivo era el socialismo y su metodología, la lucha armada (Lanusse, 2005). Lideraba la Tendencia Revolucionaria del Peronismo.

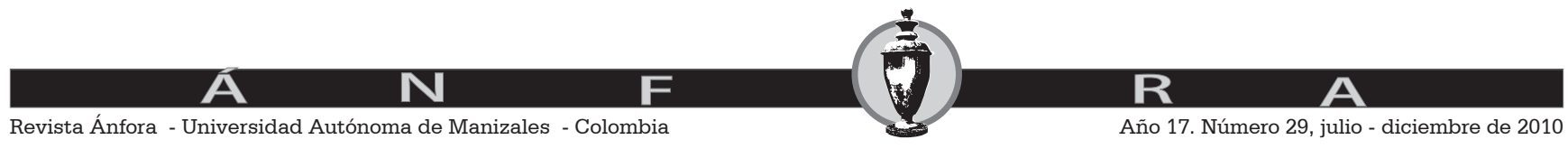


dos por un sacerdote asesor. Allí residían jóvenes varones provenientes de la zona, de los que buena parte pertenecía a la JUC y otros que no participaban de los grupos católicos e incluso no compartían la fe. Llegaban por algún contacto o recomendación de un sacerdote o propuestos por algún residente y luego el grupo que administraba el Pensionado -que era elegido por asamblea- decidía la incorporación teniendo en cuenta un cierto perfil compatible con el proyecto de vida comunitaria, que implicaba compartir los espacios comunes, las comidas, los gastos para mantener la casa, el cuidado de las instalaciones, etc. La vida en el Pensionado significó para muchos jóvenes, el (re)descubrimiento de la fe católica, su maduración en la línea de Medellín, la entrada en la JUC -por invitación de los compañeros de convivencia- y el comienzo de la militancia en diversos espacios. Así como no todos los residentes del Pensionado eran católicos, tampoco todos tenían un compromiso social o político concreto. Sin embargo, el lugar es recordado como "núcleo central de la militancia antisistémica de Bahía Blanca"26.

Los testimonios de algunos residentes del Pensionado coinciden en caracterizarlo como punto de encuentro de militantes, de discusión de ideas, frecuentemente de modo espontáneo en los ratos que dejaba libre el estudio -favorecido por el ambiente estudiantil y la vida comunitaria- y de organización de movilizaciones masivas en contra de la dictadura de Onganía.

Según los Servicios de Inteligencia, el número de residentes oscilaba "entre los 15 y los 20 estudiantes" que pertenecían "al JUC" (sic) y a su vez estaban "enrolados en distintas agrupaciones universitarias de izquierda (TERS. AUDAL. GRUPOS SOCIALISTAS. FEN)"27. En efecto, en la residencia estudiantil vivían muchos militantes universitarios y también era centro de reunión de distintas agrupaciones, lo que se veía facilitado por su ubicación, "de paso" a la Universidad y porque al no ser una casa particular daba un mayor margen de libertad para desarrollar las actividades que involucraba la militancia. Eduardo, militante jucista y estudiante de Economía que vivió en el Pensionado en el '68 y '69, recordaba las reuniones informales del PRT, que involucraban a unas pocas personas en una actividad "todavía inorgánica" y consistían en discutir y pensar "¿qué se puede hacer?" o "las posibilidades de América Latina"28. También Graciela, integrante de la JUC y estudiante de Economía, evocaba las reuniones en el lugar de Nueva Línea de Acción ${ }^{29}$. Juan Carlos recordaba que fueron algunos jóvenes pensionistas quienes formaron AUDAL.

Por otra parte, en ese lugar se distribuían publicaciones de izquierda como Cristianismo y Revolución ${ }^{30}$ y El Combatiente ${ }^{31}$. Era un espacio donde a fines de los '60 se desarrollaba una importante actividad de propaganda del PRT El Combatiente, apuntalada por la presencia del militante perretista Hugo Fuentes, desaparecido desde el 15 de febrero de 1977 (Giménez, 2008: 29).

En tanto lugar de encuentro de la militancia "antisistémica", el Pensionado Católico fue objeto de atentados y allanamientos. Los Servicios de Inteligencia registraron un allanamiento ocurrido el 22 de junio de 1971 en busca de ar-
26 Entrevista a Juan Carlos, 29/07/08. Juan Carlos era estudiante de Ingeniería Química y residente del Pensionado a fines de los '60 y principios de los '70.

27 Atentado contra el Pensionado Católico de Zapiola 428 de Bahía Blanca. Archivo DIPBA, Mesa "Referencia", Legajo $\mathrm{N}^{\circ}$ 15281, Tomo 5.

28 Entrevista a Eduardo, 16/10/08.

29 Entrevista a Graciela, 31/07/08.

30 Revista publicada entre 1966 y 1971. Se proponía difundir el pensamiento post-conciliar, defendía la opción por la lucha armada y apoyaba la Tendencia Revolucionaria del Peronismo.

31 Órgano de propaganda del PRT (Giménez, 2008).

32 Atentado contra el Pensionado Católico de Zapiola 428 de Bahía Blanca. Archivo DIPBA, Mesa "Referencia", Legajo $N^{\circ}$ 15281, Tomo 5.

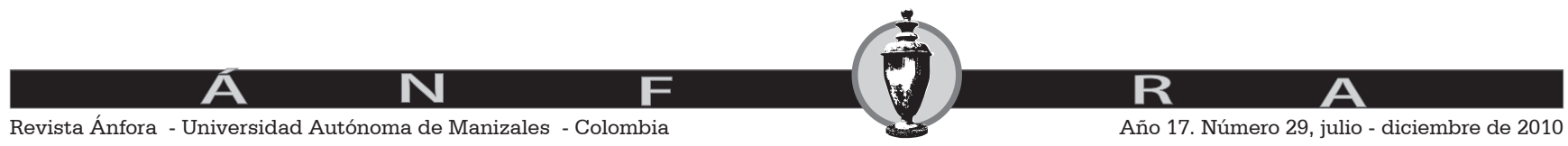


mas robadas en el polígono de Punta Alta por el ERP, durante el cual algunos residentes expresaron que presumían haber sido denunciados por un dirigente local de la Juventud Nacional Peronista, quien ya habría arrojado allí bombas de estruendo y efectuado disparos al aire ${ }^{32}$. Dos meses y medio después, el frente del edificio "fue tiroteado por elementos desconocidos. Además los autores del hecho arrojaron gran cantidad de volantes con insinuaciones anticomunistas. No hubo heridos" 33 . Los Servicios de Inteligencia no descartaban que el atentado hubiera sido perpetrado por los mismos residentes "para reafirmar una presunta persecución al estudiantado y grupo católico"34.

\section{La militancia en el barrio}

Otro de los espacios fundamentales de acción y construcción social y política de muchos de estos jóvenes católicos fue Villa Nocito, un barrio marginal de Bahía Blanca. Un informe elaborado por los Servicios de Inteligencia en noviembre de 1973 nos brinda una descripción sucinta del barrio en aquellos años. Estaba ubicado al oeste de la ciudad, a 35 cuadras del centro. Tenía una población de 376 personas, la mayoría argentinos, pero con un alto porcentaje de población chilena. El $57 \%$ de los habitantes de la villa eran menores en edad escolar. Había dos instituciones educativas: la Escuela $\mathrm{n}^{\circ} 24$ y la Escuela Nuestra Señora de la Paz. No existía ningún centro sanitario o asistencial, por lo que su creación era visualizada como una de las necesidades más urgentes del lugar. El barrio contaba con una Unidad Básica dirigida por el peronismo de izquierda y se encontraba dentro del radio de acción del Comité de Defensa Barrial Noroeste "con infiltración marxista y trotzkysta" 35 . Se destacaba la influencia en el lugar del Movimiento de Sacerdotes para el Tercer do ${ }^{36}$ a través del Padre Néstor Navarro, director de Cáritas ${ }^{37}$, y de Norma Gorriarán, hermana de la congregación Compañía de María y directora de la Escuela Nuestra Señora de la Paz. Esta última era señalada como la persona de mayor arraigo entre la gente del barrio, junto al referente peronista que dirigía la Unidad Básica ${ }^{38}$.

La acción de los militantes cristianos en Villa Nocito se desarrolló a partir de la Unidad Básica, el trabajo en Cáritas y la Escuela Nuestra Señora de la Paz. Esta última había surgido a partir de la iniciativa de la hermana Norma, que hacía un tiempo que visitaba el barrio para dar catequesis y apoyo escolar y acompañar a una hermana de su congregación que atendía un jardín de infantes, y del Padre Néstor Navarro que propusieron a Monseñor Germiniano Esorto ${ }^{39}$ convertir el edificio de una iglesia abandonada en escuela. Esorto aceptó, pero puso como condición que se celebrara misa los domingos, lo que se cumplió semanalmente en la galería de la escuela una vez construido el edificio. Ésta comenzó a funcionar con tres aulas de $1^{\circ}, 2^{\circ}$ y $3^{\circ}$ grado y teniendo como representante legal al director de Cáritas. Según registraba un medio local, la escuela fue inaugurada el 14 de marzo de 1971 con una matrícula de más de 100 alumnos ${ }^{40}$.
33 Tiros en un pensionado local. (1971, 1 de septiembre). El Eco. Archivo DIPBA, Mesa "Referencia", Legajo $\mathrm{N}^{\circ}$ 15281, Tomo 5.

34 Atentado contra el Pensionado Católico de Zapiola 428 de Bahía Blanca. Archivo DIPBA, Mesa "Referencia", Legajo No 15281, Tomo 5.

35 Los Comités de Defensa Barrial se formaron a partir del Frente Antiimperialista y por el Socialismo -organización de carácter nacional creada en 1973 bajo el impulso de militantes del PRT-ERP, como respuesta a una necesidad partidaria de profundizar el trabajo de inserción de masas. Éstos respondían a las demandas y luchas particulares de cada espacio y significaron para los vecinos una alternativa de militancia barrial basada en el trabajo democrático (Giménez, 2008).

36 Comenzó a estructurarse en 1968 a partir de la adhesión de sacerdotes de distintos puntos de la Argentina al Manifiesto de 18 obispos del Tercer Mundo. Reunió a más de 500 presbíteros (9\% del clero), de los cuales al menos un tercio se había formado durante el Concilio Vaticano II (Bresci, 1994).

37 Creada en 1969, desarrollaba una actividad comprometida e innovadora con los sectores menos favorecidos.

38 Archivo DIPBA, Mesa "Referencia", Legajo 10141, Tomo 2.

39 Esorto estuvo al frente de la Iglesia de Bahía Blanca desde 1947, como segundo obispo y como arzobispo, desde 1957 hasta julio de 1972, cuando elevó su renuncia al Papa Pablo VI en razón de alcanzar la edad límite aconsejada para la misión pastoral por el Concilio Vaticano II.

40 Escuela en Villa Nocito. (1971, 10 de marzo). El ECo.

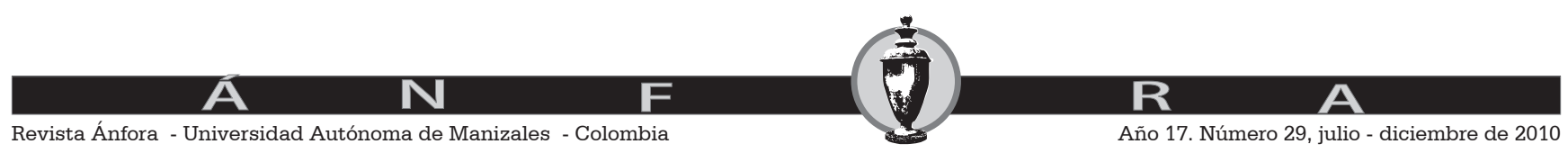


La escuela contaba con una trabajadora social, una psicopedagoga, un grado diferenciado para los alumnos que no podían integrarse a escuelas comunes porque tenían alguna discapacidad y otro para aquellos con problemas de aprendizaje que una vez superados se integraban al grado que les correspondía. Además se daba la leche a los chicos gracias a las donaciones de una planta pasteurizadora cercana. Por las noches funcionaba el Centro de Educación de Adultos $\mathrm{n}^{\circ}$ 20, a cargo de la directora de la escuela y dos maestras, donde concurría gente del barrio. Con el tiempo se construyeron más aulas y una sala para la dirección, gracias a la ayuda de los padres, vecinos y un grupo de apoyo que se acercaba a trabajar, no sólo en cuestiones materiales sino de reflexión y estudio.

Este compromiso se tornaba en algunos casos, identificación con la gente, en tanto se buscaba compartir sus problemas y formas de vida. En 1972, Norma y cuatro hermanas de su congregación alquilaron una casa prefabricada y se fueron a vivir a Villa Nocito. Algunas de ellas trabajaban en la escuela y las otras las acompañaban aunque seguían realizando sus actividades en La Inmaculada, colegio de la congregación Compañía de María ubicado en la zona céntrica de la ciudad. Estos hechos se comprenden en el proceso mayor de cambio y renovación de la vida religiosa que tenía lugar en las ciudades medianas y grandes, donde varias congregaciones femeninas empezaban a descentralizar la distribución de su personal, atendiendo zonas marginadas (Gera y Melgarejo, 1970: 80). Vivir en el barrio implicaba para las religiosas, por un lado, dejar de lado una vida sin precariedades, propia de gente proveniente de clase media; por otro, una fuerte experiencia comunitaria. Además permitía un contacto permanente con los vecinos que trascendía los problemas que tenían que ver estrictamente con la escuela.

La actividad de las maestras en el barrio también transcendía el trabajo que realizaban todas las mañanas en el aula e implicaba volver a la tarde a Villa Nocito para visitar a la gente, hablar con los padres de los alumnos, realizar un acompañamiento de sus familias e interiorizarse de la realidad de cada niño -que se veía reflejada en el aula: chicos que tenían problemas de aprendizaje, que se dormían en los bancos porque venían de trabajar vendiendo diarios, etc.-, de modo de poder llevar a cabo intervenciones adecuadas a las situaciones particulares. Marta, ex maestra de la escuela, lo definía como "nuestra manera de ser docentes"41 y Patricia, también ex docente, como la posibilidad de canalizar el deseo de "querer hacer con el otro" y de realizar la utopía de ayudar a "transformar la realidad" "metido" en el barrio, entre la gente ${ }^{42}$.

La escuela de Cáritas era un centro de referencia educativo, eclesial y de promoción humana para la gente de Villa Nocito, que frecuentemente recurría a la comunidad de hermanas y a las maestras ante distintas necesidades y urgencias: conseguir alimentos, llevar un niño al hospital en el Citroen que las hermanas habían comprado, ir a la comisaría, cuidar durante las noches a los hijos de un matrimonio que se encontraba en el hospital, yéndose a dormir a su rancho, ofrecer la escuela en época de vacaciones para que pudiera

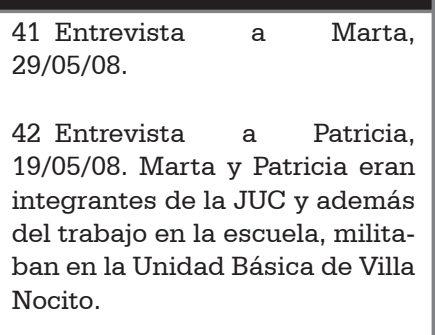

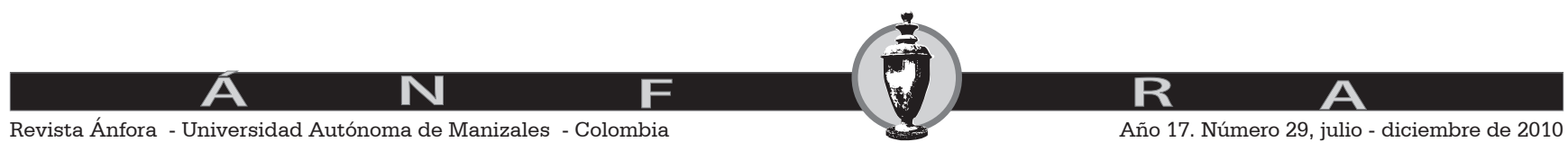


vivir una familia a la que se le había quemado su casa, organizar velorios o conseguir cajones a través de la municipalidad. También era una referencia para muchos militantes que venidos "de afuera" se acercaban al barrio para desarrollar un trabajo social o político.

La militancia en la Unidad Básica de Villa Nocito se orientaba a la mejora de la calidad de vida de la gente, a resolver sus necesidades en un barrio que aparece en el recuerdo con muchas más precariedades y carencias que las que tiene en la actualidad en términos de vivienda, infraestructura y servicios. En este marco, muchos militantes barriales, como algunas maestras de la escuela, se acercaron a la militancia política como una forma de superar el dolor o la impotencia que generaba el conocimiento de la realidad de la gente del barrio y comenzar a trabajar con otros para cambiarla, "ir a las causas". Desde allí se impulsó la lucha por la instalación de las canillas públicas, los servicios del agua potable, la luz, la gestión por la apertura de calles, la demarcación de manzanas, el reconocimiento de los terrenos para la gente que estaba asentada, etc. Para Rodolfo, militante jucista de la Juventud Peronista, se trataba de "acompañar a la gente en reclamos que tenían que ver con sus condiciones de vida y ayudar a la organización, promover la solidaridad entre ellos, acompañar esos procesos"43.

En ese espacio se encontraban la gente del barrio, los estudiantes universitarios que militaban en la JP o en Montoneros y algunas maestras de la escuela, como Patricia y Marta -quien a su vez era estudiante de Filosofía de la UNS. ,Estas docentes y muchos estudiantes eran además miembros de la JUC.

No resulta sencillo distinguir las prácticas de los militantes católicos en cada uno de los espacios de Villa Nocito cuando buena parte de estos jóvenes participaba simultáneamente de la escuela, de la Unidad Básica y, en el caso de Marta, también de la Agrupación Evita ${ }^{44}$. Además, había una especie de "conjunción de ideales" entre las distintas prácticas que hacía que, en varias oportunidades, confluyeran en actividades y disputas comunes.

Una de ellas fue la lucha por el proyectado Camino de Cintura en los primeros años de la década del '70, cuya realización implicaba el desalojo de muchas familias de Villa Nocito y la demolición de la Escuela Nuestra Señora de la Paz. Su licitación estaba pensada para principios de 1973. La toma de conciencia del problema impulsó la unión, organización y movilización de los vecinos para enfrentar colectivamente el desalojo, las presiones y los intentos de dividirlos. En este marco, sumado a otras necesidades que vivía la gente del barrio, los vecinos crearon el Comité de Defensa Barrial en 1973 (Giménez, 2008).

En esa lucha contra el Camino de Cintura se involucraron diversas agrupaciones e instituciones vinculadas al barrio. Por un lado, varias reuniones se hicieron en la Escuela Nuestra Señora de la Paz. Por otro, la gente de Cáritas, las maestras y las religiosas ligadas a la escuela imprimieron volantes con el mimeógrafo de Cáritas y salieron a repartirlos por el barrio y el centro de la ciudad planteando la resistencia a la obra. Por otra parte, Cáritas elaboró un

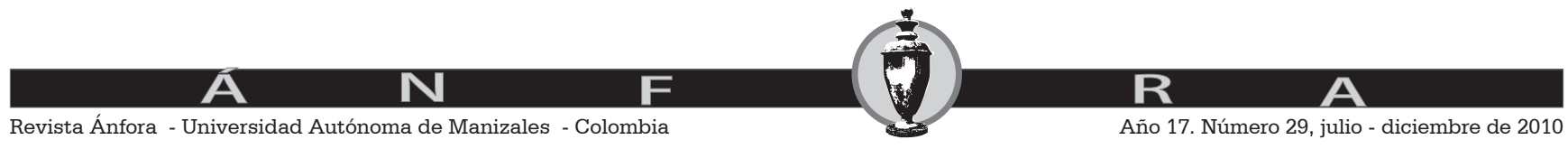


informe sobre los perjuicios que implicaba la construcción del Camino para la gente que habitaba en los barrios afectados por el proyecto, que fue presentado al gobierno municipal en agosto de 1972. Por último, también la JUC se ocupó del problema y se pronunció públicamente en contra del proyecto 45 .

Tras la muerte de Perón y bajo la acción de la Triple A, primero, y el Estado Terrorista, después, este grupo de jóvenes cristianos y los religiosos que los acompañaban se convirtieron en víctimas de persecución política, atentados, amenazas y cárcel. Entre el 21 de marzo y el 30 de abril de 1975, los principales referentes consagrados de estos jóvenes sufrieron atentados que los obligaron a abandonar la ciudad. Estas prácticas represivas sumadas a las vividas en carne propia por los jóvenes, provocaron la disolución de la JUC, el abandono por parte de sus integrantes de los espacios y prácticas que los habían constituido como sujetos y la partida al exilio interno y externo. Abril de 1975 aparece en la memoria de los protagonistas como un estallido, el inicio de la diáspora.

\section{Reflexiones finales}

Ahora bien, ¿es posible reconocer peculiaridades locales en la experiencia de la JUC? Probablemente este interrogante sea difícil de responder en el estado actual de las investigaciones. Estas particularidades no parecen evidentes. Graciela opinaba en este sentido: "creo que vivimos situaciones similares a otros en otras ciudades con iguales características de Argentina o de otros países latinoAméricanos"46.

Sin embargo, como adelantábamos anteriormente, existe una diferencia de cronología entre la experiencia bahiense del período 1967-1975 y lo que ocurre en otros puntos del país. Mientras la nueva JUC crecía y se fortalecía en Bahía Blan$\mathrm{ca}$, otros grupos estaban en crisis o habían desaparecido. Por otra parte, si bien ocurrió algo similar en otras ciudades, el rol de los asesores, y de José Zamorano en particular, fue fundamental, por su aporte en cuanto a la experiencia en los movimientos especializados y, principalmente, en la revisión de vida, por su postura eclesial en la línea del catolicismo post-conciliar, y por su actitud crítica e interpelación constante a traducir las formulaciones teóricas del compromiso cristiano en acciones y espacios concretos. En este sentido, para el Padre Zamorano, la peculiaridad de la JUC bahiense residía en que

"Había una experiencia...quizá más intensa desde el punto de vista de lo que es la pedagogía, la integración de fe y política ¿no?...me parece ¿no? que puede haber sido por ahí...de que en el tiempo una continuidad progresiva y como que...como que asimilamos bastante bien la, el carisma y la...espiritualidad de, del proyecto" ${ }^{\prime 4}$.

Como vimos, esta "integración de fe y política" se encarnó en actividades

43 Entrevista a Rodolfo,
$23 / 06 / 08$.
44 La Agrupación Evita se
constituyó en otro espacio de
encuentro y de trabajo común
en Villa Nocito que nucleaba,
en este caso, a las mujeres en
iniciativas de promoción. Estas
agrupaciones fueron creadas
hacia 1973 por Montoneros que,
en un contexto marcado por el
abandono de la lucha armada,
buscaba reorientar su estrate-
gia hacia la profundización del
trabajo político con los sectores
populares. Ello era fundamental
para desbancar a la ortodoxia
peronista y de ese modo obte-
ner el control del movimiento
(Freytes, 2008).
45 Bahía Blanca ¿Polo de cre-
cimiento? (1972, noviembre).
Revista Graphos, Bahía Blanca,
año III, no 11.
46 Graciela, (comunicación per-
sonal, 13/08/09).
47 Entrevista a José Zamorano,
19/09/09.

47 Entrevista a José Zamorano,
19/09/09.

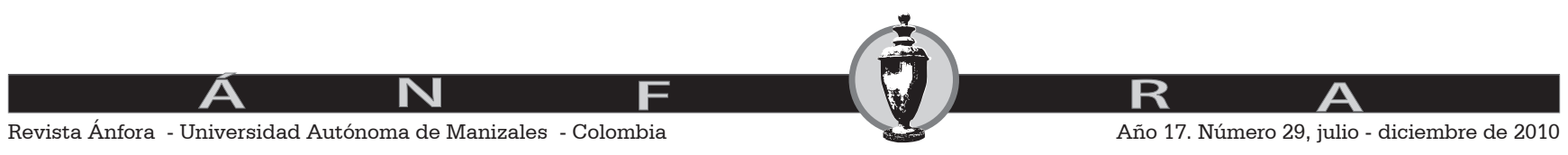


y lugares específicos. El intento de reconstrucción de la militancia jucista en dos espacios fundamentales, como lo fueron la Universidad y el barrio, pone de manifiesto las dificultades de separar la historia de la JUC de la de toda una red de personas e instituciones del catolicismo post-conciliar a nivel local. En Villa Nocito, integrada por la Escuela Nuestra Señora de la Paz, Cáritas y la figura de Norma Gorriarán, que como religiosa, se constituyó en referente de compromiso cristiano para muchos de estos jóvenes. Por otra parte, tampoco resulta sencillo escindir la acción jucista en el ámbito barrial o estudiantil del movimiento más amplio de activación juvenil de los años '60 y '70 en Bahía Blanca.

Entonces ¿en qué medida la militancia de los jóvenes jucistas tenía peculiaridades que permitían identificarla dentro de la militancia revolucionaria bahiense? ¿Es posible pensar en un cierto "estilo" de militancia que los diferenciaba, tal como parece sugerir el calificativo "cristianuchis" con el que eran identificados por los compañeros de la JUP? Esto es, si sus compañeros de militancia los reconocían como un grupo, ¿qué particularidades los constituían como tal? Sin pretender agotar la discusión es posible adelantar algunas reflexiones.

En primer lugar, la mayor parte de estos jóvenes descubrieron la militancia desde los grupos cristianos y las prácticas que asumieron como consecuencia encontraron impulso y justificación en una determinada visión de la fe: encarnada/comprometida con la realidad. Para Nora, militante jucista en Villa Nocito, la militancia política fue un "descubrimiento desde los grupos cristianos" 48 . Por su parte, Juan Carlos planteaba que su militancia universitaria tenía como motivación central "el amor a Jesús encarnado en la historia... eso era, construir un Reino más justo"49. Según Graciela, "la JUC nos unía el creer que $[\ldots]$ que ser cristiano era vivir la fe de manera comunitaria, que eso teníamos que evangelizar de alguna manera en el medio en que estábamos y en la línea de compromiso con los pobres" 50 . Usando las palabras de Mónica, si bien existían múltiples formas de incorporarse a la ola revolucionaria, este grupo de militantes se subió a la ola entrando por un determinado costado.

Por otra parte, los militantes católicos compartían un lugar y un ejercicio de reflexión continua de sus prácticas, que se constituyó en espacio de identificación y pertenencia, paralelo al grupo de acción propiamente dicho. Hasta mediados de los '70, la participación simultánea en los dos ámbitos ligados a la fe y a la militancia, se alimentaba y justificaba mutuamente. Además, esa reflexión que los llevaba a la acción partía de la realidad y no de doctrinas preestablecidas. Esto es, la pedagogía de la revisión de vida dejó su impronta desde el punto de vista político y epistemológico. El Ver, Juzgar, Actuar suponía un pensamiento situado. La reflexión en torno a una situación particular no podía subsumirse a marcos teóricos estructurados, aunque se sirviera de principios e ideas diversas.

A pesar de estos rasgos compartidos, que los constituían como grupo identificable entre otros militantes, no eran un colectivo homogéneo. La hetero-
48 Entrevista a Nora, 04/06/08.

49 Entrevista a Juan Carlos, 01/08/08.

50 Entrevista a Graciela, $31 / 07 / 08$.

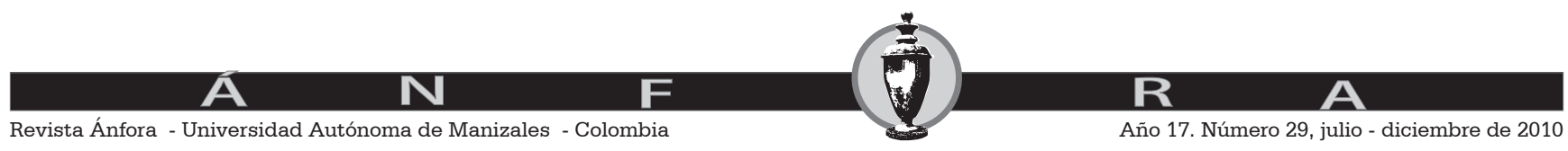


geneidad estaba dada por la convivencia de distintas opciones en cuanto a los espacios de compromiso (la universidad, el barrio, el lugar de trabajo, la Iglesia), las modalidades de acción (la militancia social, política -si fuera posible separarlas-, armada, eclesial) y las trayectorias político-ideológicas asumidas. Y esta diversidad del grupo, tanto en lo relacionado con las formas de compromiso asumidas como con las opciones políticas, estuvo en el origen de una serie de conflictos internos que marcaron a la JUC durante estos años.

Por otro lado, estos jóvenes eran "hijos de su tiempo", por lo que compartían las características de su generación. De allí que la renovación eclesial y su fe encarnada no sean suficientes para explicar su pensamiento y práctica antisistémica. Además, se reconocían formando parte de un colectivo mucho más amplio y diverso de jóvenes que optaban por un proyecto social alternativo. Como cristianos se veían compelidos a definirse, comprometerse y actuar, pero no desde una organización particular sino mezclados con los no cristianos, ya que "el cambio de estructuras deben producirlo todos los hombres". Y en esa obra, "el cristianismo no proporciona base ideológica o cultural" sino un "sentido religioso" (Habegger, 1970: 169).

Así, Villa Nocito y la UNS fueron espacios centrales de la militancia bahiense, donde confluyeron las prácticas de militantes provenientes de diversas tradiciones, entre los cuales, buscando ser "fermento en la masa", mezclados y a veces confundidos con los otros, los jóvenes jucistas dejaron su impronta. De allí que la descripción de los espacios de militancia católica haya sido en gran medida un aporte a la reconstrucción de la militancia bahiense en general.

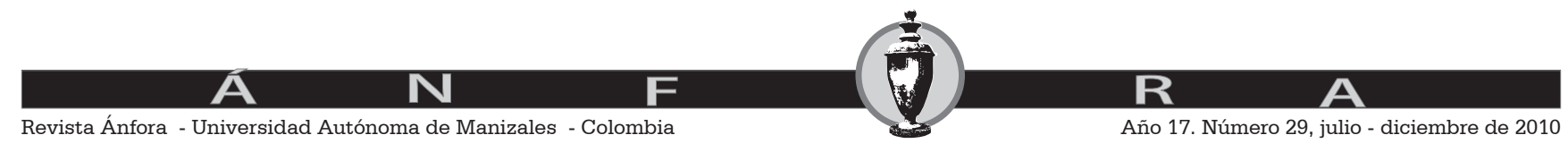




\section{Bibliografía}

Bozza, J. (2002). El peronismo revolucionario. Itinerario y vertientes de la radicalización, 1959-1969. Sociohistórica, Cuadernos del CISH, 9/10,135-169.

Bresci, D. (1994). Movimiento de Sacerdotes para el Tercer Mundo. Documentos para la memoria histórica. Buenos Aires, Argentina: Centro Salesiano de Estudios San Juan Bosco, Centro Nazaret, CEHILA.

Burkart, M. (2007, septiembre). La dictadura militar y su proyecto de transformación cultural. En CD de XI Jornadas Interescuelas/Departamentos de Historia, Universidad Nacional de Tucumán, Tucumán, Argentina.

Cattaruzza, A. (1997). El mundo por hacer. Una propuesta para el análisis de la cultura juvenil en la Argentina de los años setenta. Entrepasados, 13, 103-114.

De Riz, L. (1987). Retorno y derrumbe. El último gobierno peronista. Buenos Aires, Argentina: Hyspamérica.

Freytes, N. (2008, mayo). Mujeres que hicieron historia. Un acercamiento a la militancia estudiantil y política de los años '70 desde la historia oral. En CD de IV Jornadas de Trabajo sobre Historia Reciente, Universidad Nacional de Rosario, Rosario, Argentina.

Gera, L. y Rodríguez Melgarejo, G. (1970). Apuntes para una interpretación de la iglesia argentina. Montevideo, Uruguay: Ediciones Centro de Documentación MIEC-JECI.

Giménez, M. J. (2008). Ciudad de "Perros". Historias de militancia y recorridos del PRT-ERP por la ciudad de Bahía Blanca. Tesis de Licenciatura en Historia no publicada, Universidad Nacional del Sur, Bahía Blanca, Argentina.

Giménez Béliveau, V. (2005). Sociabilidades de los laicos en el catolicismo en la Argentina. Un recorrido socio-histórico. Prismas. Revista de Historia Intelectual, 9, 217-227.

Lanusse, L. (2005). Montoneros. El mito de los doce fundadores. Buenos Aires, Argentina: Vergara.

Mallimaci, F. (1992). El catolicismo argentino desde el liberalismo integral a la hegemonía militar. En AA.VV., 500 años de cristianismo en Argentina. Buenos Aires, Argentina: CEHILA-Centro Nueva Tierra.

Mallimaci, F., Cucchetti, H. y Donatello, L. (2006). Caminos sinuosos: nacionalismo y catolicismo en la Argentina Contemporánea. En Francisco Colom y Angel Rivero (edit), El altar y el trono. Ensayos sobre el catolicismo político latinoAméricano. Barcelona, España: ANTROPHOS/UNIBIBLOS.

Habegger, N., (1970) Apuntes para una historia. En Mayol, A., Habegger, N. y Armada, A., Los católicos posconciliares en la Argentina. Buenos Aires, Argentina: Editorial Galerna.

Orbe, P. (2007). La política y lo político en torno a la comunidad universitaria bahiense (19551976). Estudio de grupos, ideologías y producción de discursos. Tesis doctoral no publicada, Universidad Nacional del Sur, Bahía Blanca, Argentina.

Politi, S. (1992). Teología del Pueblo. Una propuesta argentina a la teología latinoAméricana. 1967-1975. Buenos Aires, San Antonio de Padua, Argentina: Editorial Guadalupe/ Ediciones Castañeda.

Segunda Conferencia General del Episcopado LatinoAméricano. Medellín. Septiembre de 1968. (III Edición). (1969). Documentos Finales. Quisquizacate, Argentina: Talleres Tipográficos de la Pía Sociedad de San Pablo.

Zapata, A. B. (2008). Páginas Manchadas. Conflictividad laboral entre los gráficos y La Nueva Provincia en vísperas de la dictadura de 1976. Tesis de Licenciatura en Historia no publicada, Universidad Nacional del Sur, Bahía Blanca, Argentina.

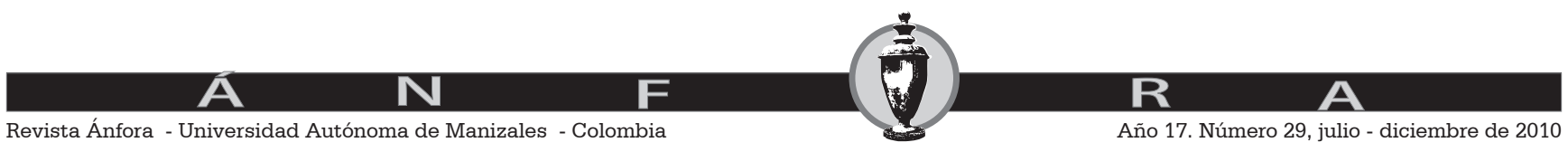

